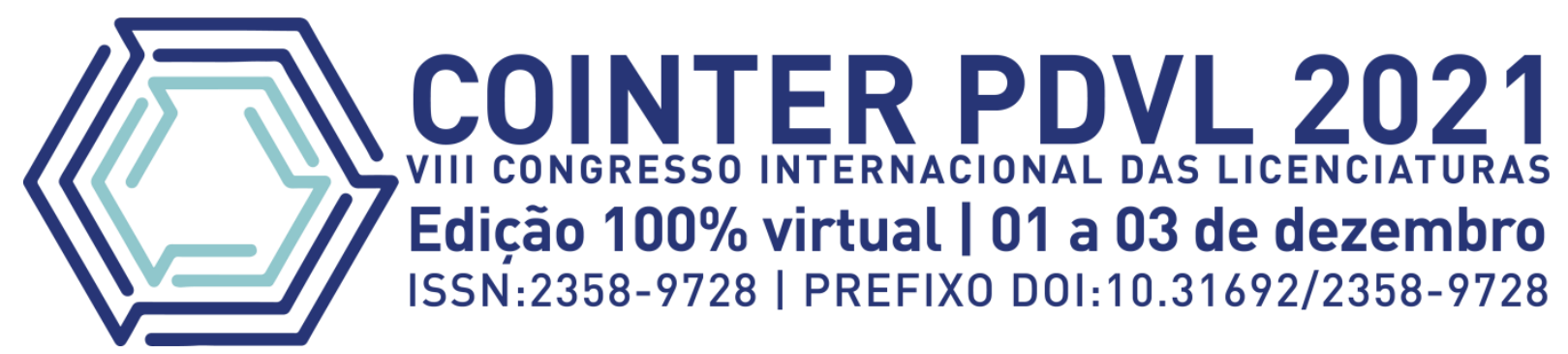

\title{
APLICAÇÃO DE TEMAS NORTEADORES NO ENSINO DE QUÍMICA POR MEIO DE UMA ABORDAGEM INTERDISCIPLINAR
}

\author{
APLICACIÓN DE TEMAS ORIENTADORES EN LA ENSEÑANZA QUÍMICA A \\ TRAVÉS DE UN ENFOQUE INTERDISCIPLINARIO
}

\section{APPLICATION OF GUIDING THEMES IN CHEMISTRY TEACHING THROUGH AN INTERDISCIPLINARY APPROACH}

Apresentação: Comunicação Oral

\author{
Evany Mikaelly Cardoso Soares ${ }^{1}$; Joyce dos Santos Farias²; Davi Vieira Correia ${ }^{3}$; Ândello Mychael Ferreira \\ Soares da Silva ${ }^{4}$ Alessandra Marcone Tavares Alves de Figueirêdo ${ }^{5}$
}

\section{RESUMO}

DOI: https://doi.org/10.31692/2526-7701.VIIICOINTERPDVL.0222

Uma das premissas das universidades públicas e privadas é formar profissionais para atuarem diretamente no mercado de trabalho, este está em constante modernização e progresso, o que consequentemente, exige pessoas mais capacitadas e com mais informações sobre diversos temas. Sendo assim, o Programa de Educação Tutorial - PET Química do Instituto Federal da Paraíba - IFPB, Campus João Pessoa, Brasil, desenvolveu uma atividade denominada "Ciclo de Palestras", designada aos discentes do Curso de Licenciatura em Química desta instituição, com a finalidade de trabalhar temas interdisciplinares que não estão presentes na matriz curricular, agregando conhecimento científico e despertando um olhar crítico do discente participante. Dessa forma, o presente trabalho utilizou uma metodologia qualitativa, contendo três momentos: i) Aplicação do Questionário de Sondagem (QS); (ii) Duas palestras ministradas intituladas: "A Química das cores, por que enxergamos o mundo colorido?" e "Química Forense: desvendando crimes"; (iii) Aplicação do Questionário Final (QF). Vale destacar ainda, que em virtude da pandemia do Covid-19 vivenciada por toda a população mundial, as etapas realizadas ocorreram todas de forma virtual. Nos resultados, foi possível constatar a relevância da atividade, bem como o desenvolvimento dos discentes por meio das palestras ministradas. No QS alguns estudantes conheciam de formar superficial as temáticas, mas não conseguiam relacioná-las com os conceitos científicos. Durante a ministração das palestras, ocorreram diversos debates e discussão entre os participantes e os ministrantes, havendo uma correlação dos conceitos químicos e os temas das palestras, contribuindo assim, com resultados satisfatórios no QF. Além disso, tal atividade pôde corroborar com os próprios discentes PETianos, uma vez que o ensinar estimula o aprender e a troca de saberes é algo imprescindível no processo de ensino e aprendizagem dos estudantes.

Palavras-Chave: Química, Cores, Forense, Ciclo de Palestras.

\footnotetext{
${ }^{1}$ Licenciatura em Química, Instituto Federal da Paraíba- IFPB, mikaelly.cardoso@ academico.ifpb.edu.br

${ }^{2}$ Licenciatura em Química, Instituto Federal da Paraíba- IFPB, santos.joyce@academico.ifpb.edu.br

${ }^{3}$ Licenciatura em Química, Instituto Federal da Paraíba-IFPB, davi.vieira@academico.ifpb.edu.br

${ }^{4}$ Licenciatura em Química, Instituto Federal da Paraíba- IFPB, silva.andello@ academico.ifpb.edu.br

${ }^{5}$ Doutora em Química, Instituto Federal da Paraíba-IFPB, alessandratavaresfigueredo@academico.ifpb.edu.br
} 


\section{RESUMEN}

Una de las premisas de las universidades públicas y privadas es formar profesionales para trabajar directamente en el mercado laboral, que se encuentra en constante modernización y avance, lo que en consecuencia requiere de personas más calificadas y con más información en diversos temas. Así, el Programa de Educación Tutorial - PET Química del Instituto Federal de Paraíba - IFPB, Campus João Pessoa, Brasil, desarrolló una actividad denominada "Ciclo de Conferencias", destinada a los estudiantes de la Licenciatura en Química de esta institución, con el propósito trabajar en temas interdisciplinarios que no están presentes en el plan de estudios, agregando conocimientos científicos y despertando una mirada crítica del alumno participante. De esta forma, el presente trabajo utilizó una metodología cualitativa, conteniendo tres momentos: i) Aplicación del Cuestionario de Encuesta (QS); (ii) Dos conferencias impartidas tituladas: "La química de los colores, ¿por qué vemos el mundo en color?" y "Química forense: desenmarañando crímenes"; (iii) Aplicación del Cuestionario Final (QF). También vale la pena señalar que, debido a la pandemia de Covid-19 que vivió toda la población mundial, las medidas tomadas se llevaron a cabo prácticamente. En los resultados se pudo constatar la relevancia de la actividad, así como el desarrollo de los estudiantes a través de las conferencias impartidas. En el QS, algunos estudiantes conocían los temas de manera superficial, pero no podían relacionarlos con conceptos científicos. Durante la entrega de las conferencias, hubo varios debates y discusiones entre los participantes y los profesores, con una correlación entre los conceptos químicos y los temas de las conferencias, contribuyendo así con resultados satisfactorios en el QF. Además, esta actividad podría corroborarse con los propios alumnos de PETianos, ya que la docencia estimula el aprendizaje y el intercambio de conocimientos es fundamental en el proceso de enseñanza y aprendizaje de los alumnos.

Palabras Clave: Química, Colores, Forense, Universidades.

\section{ABSTRACT}

One of the premises of public and private universities is to train professionals to work directly in the labor market, which is in constant modernization and progress, which consequently requires more qualified people with more information on various topics. Thus, the Tutorial Education Program - PET Chemistry of the Federal Institute of Paraíba - IFPB, Campus João Pessoa, Brazil, developed an activity called "Cycle of Lectures", designated to students of the Licentiate Degree in Chemistry at this institution, for the purpose to work on interdisciplinary themes that are not present in the curriculum, adding scientific knowledge and awakening a critical look from the participating student. Thus, the present work used a qualitative methodology, containing three moments: i) Application of the Survey Questionnaire (QS); (ii) Two lectures given entitled: "The Chemistry of Colors, why do we see the world in color?" and "Forensic Chemistry: Unraveling Crimes"; (iii) Application of the Final Questionnaire (QF). It is also worth noting that, due to the Covid-19 pandemic experienced by the entire world population, the steps taken were all virtually carried out. In the results, it was possible to verify the relevance of the activity, as well as the development of the students through the lectures given. In the QS, some students knew the themes superficially, but could not relate them to scientific concepts. During the delivery of the lectures, there were several debates and discussions between the participants and the lecturers, with a correlation between the chemical concepts and the themes of the lectures, thus contributing with satisfactory results in the QF. In addition, this activity could corroborate with the PETianos students themselves, since teaching stimulates learning and the exchange of knowledge is essential in the teaching and learning process of students.

Keywords: Chemistry, Colors, Forensics, Universities.

\section{INTRODUÇÃO}

Diante dos desafios apresentados atualmente, as universidades públicas e privadas se encontram com uma responsabilidade para formar profissionais que atuem de frente com as 
informações e mudanças que vêm ocorrendo. Atrelada a essa premissa, surge a necessidade do desenvolvimento de temas contextualizados, que além de despertar o interesse dos educandos e uma aprendizagem crítica e científica, forme cidadãos aptos para assumirem novos papéis.

Sob esse viés, a Química é uma disciplina que não se encontra limitada somente a práticas laboratoriais, ou seja, está diretamente conectada ao nosso cotidiano, e pode explicar diversos fenômenos e causas que acontecem em nosso dia a dia, dentre eles, a forma em que enxergamos o mundo colorido e a resolução ou compreensão de assuntos de natureza judicial.

Nessa conjuntura, o Programa de Educação Tutorial - PET Química, do Instituto Federal da Paraíba - IFPB, Campus João Pessoa, Brasil, desenvolveu uma atividade de ensino denominada "Ciclo de Palestras", a qual trabalha com temas que não são vistos ou pouco vistos durante o período de graduação dos licenciandos em Química. Foram apresentadas duas palestras intituladas: 1) "A Química das cores, por que enxergamos o mundo colorido?" e 2) "Química Forense: desvendando crimes". A supramencionada atividade, tem como propósito fomentar o interesse nos assuntos em questão, aumentando sua merecida visibilidade de temáticas não comumente usuais na matriz curricular desse público acadêmico.

Nessa perspectiva, as abordagens temáticas demonstram contribuir para realidade do discente, focando em situações do cotidiano como uma alternativa fecunda de melhorar a qualidade do ensino de Química, de modo a construir uma visão mais organizada e sistematizada aos saberes sociais.

Destarte, o objetivo desse trabalho foi apresentar a atividade de ensino "Ciclo de Palestras", aos discentes graduandos do curso de Licenciatura em Química do Instituto Federal da Paraíba, Campus João Pessoa, de forma contextualizada e interdisciplinar.

\section{FUNDAMENTAÇÃO TEÓRICA QUÍMICA FORENSE E A EDUCAÇÃO}

A Química Forense é considerada uma área das ciências forences que se utiliza de produção de materiais para justiça, tendo em vista análise minuciosa de substâncias variadas, como drogas ilícitas e lícitas, resíduos de armas de fogo, venenos, combustíveis, fibras, entre outros (ROMÃO, et al., 2011). Segundo Mota e Vitta (2014, p. 1), “a Química Forense pode ser definida como a aplicação de conhecimentos químicos em auxílio à justiça na resolução de assuntos de natureza criminosa". Para Karger et al. (1975), o aumento contínuo de crimes ocasionou em um crescimento exponencial do sistema de justiça criminal e da ciência forense. 
A iniciação à Química Forense ganhou destaque nos tempos atuais com séries de TV e seriados, como CSI (Crime Scene Investigation) e Bones. Tal fato contribuiu para que os conhecimentos científicos fossem expostos de forma natural ao público, despertando o interesse nesse ramo da ciência forense (MOTA; VITTA, 2014).

Na perspectiva do ensino de Química, Santos e Amaral (2020) afirmam que a química forense no ensino de química comporta-se com tema contextualizador, evidenciando que os alunos compreendem mais facilmente conteúdos químicos abordados juntamente com a temática. Somado a isso, esses autores, em sua pesquisa envolvendo a Química Forense e Educação, discorrem que a motivação e o interesse por parte dos discentes quanto à temática vigente é possível, desde que o tema seja tratado com estratégias e ferramentas diversificadas (2020).

Em alusão à prática, Almirall (2005) destaca que, apesar dos programas de televisão que ilustram conteúdos sobre Química Forense atraiam a atenção, laboratórios forenses continuam com falta de investimento e profissionais capacitados. Logo, se faz urgente e necessário investir em infraestrutura e na capacitação de profissionais no intuito de colaborar com a justica no desvendamento de crimes.

\section{QUÍMICA DAS CORES}

A estrutura ocular pode explicar como o ser humano responde aos estímulos das cores. Brown (2005, p. 315), afirma que "a retina contém células fotorreceptoras conhecidas como bastonetes e cones". Os bastonetes (células fotossensíveis) captam diferentes picos de sensibilidade em torno do vermelho, verde e azul (do inglês Red, Green e Blue) (HELFER, et al., 2017).

As cores e as luzes se correlacionam com conceitos conhecidos da Física e Química, que são as radiações eletromagnéticas. A luz visível é um tipo de radiação eletromagnética. A luz vísivel participa do espectro eletromagnético, possuindo características singulares como comprimento de onda $(\lambda)$, frequência ( $v$ ) e velocidade da luz (c) (ATKINS; JONES, 2018). A frequência relaciona-se inversamente proporcional ao comprimento de onda, enquanto que, este relaciona-se diretamente proporcional à velocidade da luz. O quadro 1 demonstra a fórmula matemática relacionada com as ondas eletromagnéticas:

\begin{tabular}{|l|l|}
\hline \multicolumn{2}{|c|}{ Fórmula de Onda de uma Radiação Eletromagnética } \\
\hline Equação & $\square \square=\frac{c}{v}$ \\
\hline Variáveis da Equação & $\square$ - comprimento de onda \\
\hline
\end{tabular}




\begin{tabular}{|l|l|}
\hline & $\begin{array}{l}\square \text { - frequência } \\
c \text {-velocidade da luz }\end{array}$ \\
\hline
\end{tabular}

$$
\lambda=\frac{c}{v}
$$

Nesse sentido, o fenômeno das cores pode apresentar justificativas diferentes para a percepção feita pelo indivíduo, como as cores em: compostos químicos (soluções), objetos, e em compostos orgânicos.

Em compostos químicos (soluções), a substância absorve radiação eletromagnética (comprimento de onda da faixa do vísivel), que quando subtraída, o resto da luz é refletido e observa-se a cor complementar. Por outro lado, em objetos opacos, observa-se a cor que é refletida, por meio da reflexão seletiva da luz. E por último, nos compostos orgânicos, as cores podem ser observadas quando se tem ligações $\pi$ disponíveis na estrutura do composto. No momento em que a luz recai sobre a molécula, podem ocorrer excitações de elétrons do orbital molecular ligante de maior energia (HOMO, do inglês Highest Occupied Molecular Orbital), para o orbital molecular antiligante de menor energia (LUMO, do inglês Lowest unoccupied Molecular Orbital), ou seja, transições do tipo $\pi \rightarrow \pi *$, ou transições do tipo n $\rightarrow \pi *$ (orbitais não ligantes para orbitais antiligantes) (HENRIQUE, et al., 2019; MARTINS; SUCUPIRA, 2015).

\section{METODOLOGIA}

O respectivo trabalho embasou-se nas metodologias participante e qualitativa, na última o pesquisador "é ao mesmo tempo o sujeito e o objeto de suas pesquisas" (DESLAURIERS, 1991, p. 58). Enquanto que, a metodologia participante "caracteriza-se pelo envolvimento do pesquisador pelos sujeitos investigados, por meio da combinação da análise documental e a participação e observação direta dos envolvidos" (LUDKE; ANDRÉ, 1986). Deste modo, as metodologias implicam como uma validação aos fatos expostos.

No ano de 2020 (dois mil e vinte), o mundo deu início a uma jornada de combate a proliferação do vírus Sars-CoV-2, responsável pela COVID-19. Em decorrência do avanço do mesmo, efetuou-se o fechamento das redes de ensino. Paralelo a essa situação, as atividades desenvolvidas pelo PET Química, do Instituto Federal da Paraíba, Campus João Pessoa, Brasil, transcorreram por intermédio das plataformas digitais, "Google Meet" e "Google Forms".

Dessa forma, a atividade de ensino aplicada designou-se "Ciclo de Palestras", 


\section{TEMAS NORTEADORES NO ENSINO DE QUÍMICA}

realizada no período matutino, no mês de abril de 2021, e foi destinada aos discentes do curso de Licenciatura em Química da supramencionada instituição. Tal atividade tem como prioridade uma disseminação de temas diversificados na área de Química, no qual muitas vezes não são vistos durante a graduação.

O planejamento da atividade se deu por intermédio da escolha das temáticas que seriam apresentadas, em que a seleção dos temas adveio de 2 (dois) integrantes do PET Química. À vista disso, as temáticas selecionadas para as duas palestras foram: "A Química das cores, por que enxergamos o mundo colorido?" e "Química Forense: desvendando crimes". Para o desenvolvimento dessas, realizaram-se pesquisas bibliográficas sobre os conceitos específicos, buscando também relações interdisciplinares com outras áreas do conhecimento, a fim de demonstrar que as áreas do conhecimento se complementam.

Portanto, o "Ciclo de Palestras" teve uma duração de 2 (duas) horas, dividido em 50 (cinquenta) minutos para cada palestra, seguido de 10 (dez) minutos dedicados às considerações e contribuições. O público participante discorreu de 30 (trinta) licenciandos em Química, que estavam distribuídos entre o $1^{\circ}$ (primeiro) e $8^{\circ}$ (oitavo) períodos do curso, com uma média de idade entre 19 (dezenove) a 42 (quarenta e dois) anos.

A priori, foi viabilizado aos participantes um Questionário de Sondagem (QS), por meio do "Google Forms" que continha apenas 1 (uma) questão para o discente mencionar a evocação livre de palavras sobre o que lhe vinha a mente referente aos respectivos temas propostos. Dando sequência, foram realizadas as palestras de forma contextualizada e interdisciplinar, posteriormente, aplicou-se um Questionário Final (QF) que apresentava 4 (quatro) indagações referentes às palestras ministradas. Deste modo, avaliamos a concepção dos alunos sobre as temáticas apresentadas, por meio das metodologias qualitativa.

\section{RESULTADOS E DISCUSSÃO}

Diante das dificuldades enfrentadas atualmente no âmbito educacional, tendo em vista o momento pandêmico que estamos vivenciando, as tecnologias vêm sendo utilizadas como métodos eficazes para auxiliar professores e discentes no processo de ensino e aprendizagem. Nesse sentido, as plataformas digitais, como por exemplo, "Google Meet" e "Google Forms" têm ajudado de forma significativa a classe educacional. Em relação a isso, os instrumentos de avaliação, Questionário de Sondagem e Questionário Final, foram entregues e respondidos pelos discentes por meio dessas plataformas.

Vale ressaltar que os dados evidenciados no QS e QF foram analisados e se encontram 
descritos na sequência, identificados pela combinação entre a letra Q, maiúscula, seguida por um numeral correspondente a cada questionário respondido, com a finalidade de manter o anonimato dos graduandos investigados.

E para o QS e QF, que foram usados como instrumentos de avaliação investigativos, utilizou-se a Técnica de Associção Livre de Palavras (TALP) que está relacionada a ideias ou emoções por meio da proximidade ou semelhança. De acordo com Merten (1992), conforme citado por De Lima Coutinho e Do Bú (2017) “A TALP possui em sua gênese elementos constitutivos advindos das compreensões filosóficas de Aristóteles sobre a associação de ideias, através da qual originou-se o que se chama de Teoria Associacionista da Memorização". Portanto, para a análise dos resultados obtidos nos instrumentos de avaliação foram observadas as palavras que possuíam um encadeamento com o tema.

A priori, no primeiro momento da atividade, foi disponibilizado o QS com uma questão para os estudantes participantes, por meio da plataforma digital "Google Forms", que se referia a primeira palestra "A Química das cores, por que enxergamos o mundo colorido", com o intuito de analisar os conhecimentos prévios dos discentes sobre a temática citada e, dessa forma, propiciar um determinado conhecimento do público ao palestrante.

Em alusão à indagação do QS, para a primeira palestra: Quando você pensa sobre a Química das cores, o que lhe vem rapidamente em mente? Cite 5 (cinco) palavras em que você pode associar a esse termo. Esse questionamento serviu para analisar se o alunado associaria de forma análoga com a Química. Apenas 38\% dos estudantes conseguiram contextualizar os conteúdos químicos com a temática, como podemos observar no Q6 e Q8, respectivamente: "Comprimento de onda, frequência, absorção, luz branca e fótons"; "Luz, fóton, excitação dos elétrons, região do visível e comprimento de onda". Por outro lado, 62\% responderam de maneira imprecisa, como podemos comprovar no Q5: "Lápis, vermelho, tinta, desenho e paisagem".

Esse feedback nos remete a grande importância da exposição e associação dessa temática nos cursos superiores de Química, uma vez que, esse conteúdo é ministrado de maneira sucinta, sem explorar as inúmeras possibilidades que estão ligadas a ele.

Nesse contexto, acredita-se que no ensino, existem muitas alternativas para a abordagem do tema cores, pois o campo conceitual que o envolve abrange muitos tópicos da área de Ciências (KRAISIG; BRAIBANTE; PAZINATO, 2017).

Concernente ao questionamento do QS referente à segunda palestra "Química Forense, desvendando crimes": Quando você pensa no termo "Química Forense", o que lhe vem rapidamente em mente? Cite 5 (cinco) palavras em que você pode associar a esse termo. 
$40 \%$ dos discentes associaram corretamente com o assunto mencionado, os demais (60\%) obtiveram resultados incertos, como demonstra o Quadro 2, o que valida o desconhecimento sobre a temática.

Quadro 2: Resultado do Questionário de Sondagem da segunda palestra “Química Forense, desvendando crimes".

\begin{tabular}{|c|c|c|}
\hline Questionário & Associou com a temática & $\begin{array}{c}\text { Não associou com a } \\
\text { temática }\end{array}$ \\
\hline Q1 & Perícia. & Brilho. \\
& Toxicologia. & Lâmpada. \\
& Impressão digital. & Criminal Minds. \\
& Reação Química. & Ferramenta. \\
& Testes colorimétricos. & Materiais. \\
\hline Q2 & Crime. & Crimes. \\
& Investigação. & Sangue. \\
& Provas. & Tiros. \\
& Reações químicas. & Morte. \\
& Toxicologia. & Desvendar crimes. \\
\hline
\end{tabular}

Fonte: Própria (2021).

As respostas adquiridas nesse questionamento evidenciam o déficit existente deste tema no ensino de Química. Segundo Lima et al, (2016), a utilização da Química Forense no ensino desperta um maior interesse acerca dos conteúdos químicos, de forma que, os discentes construam um pensamento mais crítico, criando possibilidades de maior interação e participação por meio de estratégias didáticas de ensino, de forma contextualizada, fazendo uso de temas interdisciplinares como suporte metodológico.

Sob essa perspectiva, os resultados evidenciados nos QS das duas palestras, demonstram o desprovimento de temas que envolvam a "A Química das Cores" e a "Química Forense" durante a graduação, visto que a porcentagem de pessoas que associaram os temas citados com a Química foi extremamente ínfima. Portanto, os dados investigativos dos QS nos remetem a importância de ministrar temas transversais na Licenciatura em Química.

No segundo momento da atividade, foram ministradas as palestras (Figuras 1 e 2) por meio da plataforma digital "Google Meet", com uma duração de 50 (cinquenta) minutos cada. Em relação à primeira palestra, foram discorridos tópicos referentes à luz, sistema de cores, fenômenos ligados a visão, entre outros. E na segunda palestra, foi pautado sobre o contexto histórico e métodos químicos que contribuem na apuração dos fatos forenses.

Figura 1: Palestra sobre "A Química das Cores". 


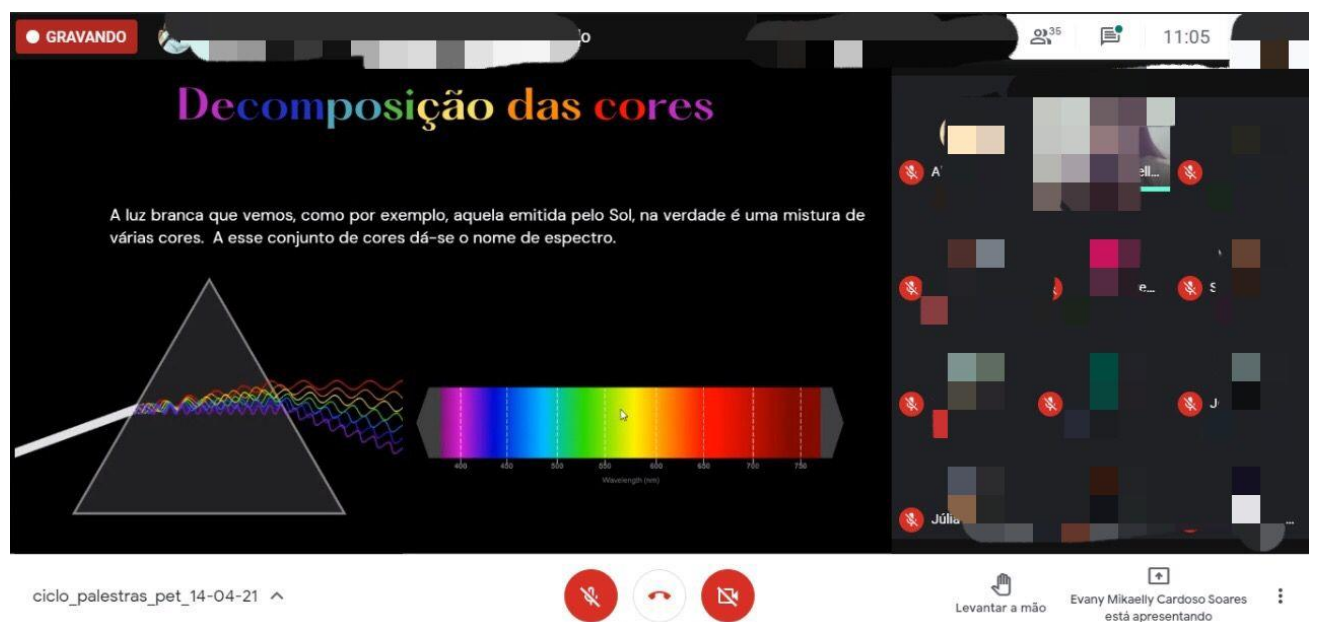

Fonte: Própria (2021).

Figura 2: Palestra sobre "Química Forense".

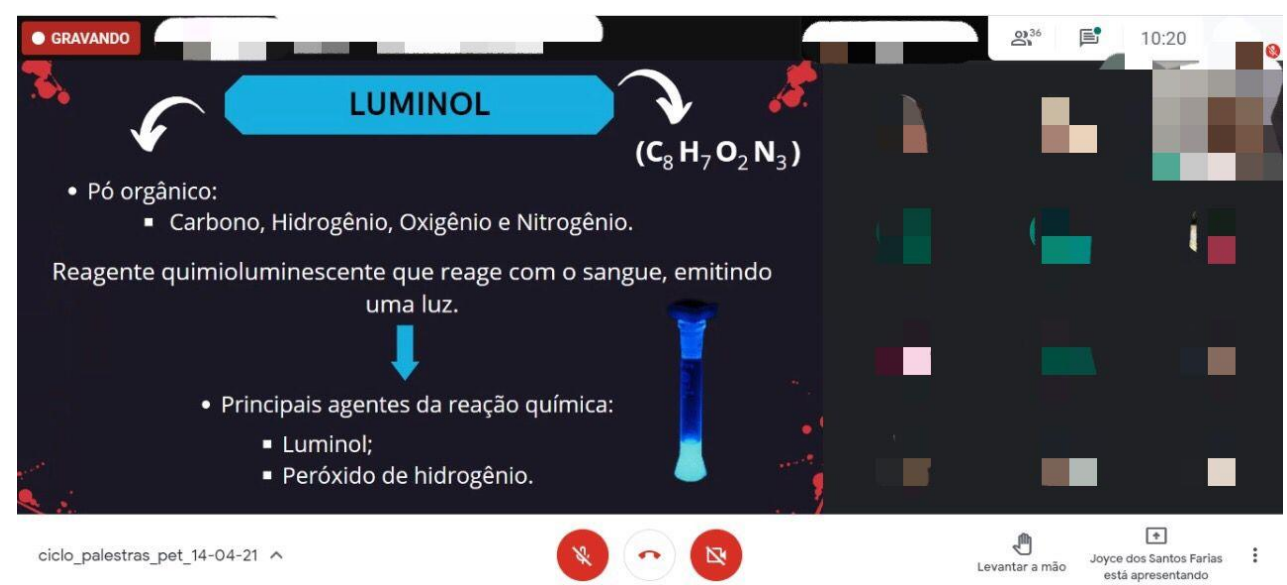

Fonte: Própria (2021).

Ambas as palestras foram ministradas de forma contextualizada, com enfoque na interdisciplinaridade, em que foram estabelecidas relações com áreas distintas de conhecimento e suas associações recorrentes com a ciência Química. Além disso, foram realizadas conexões com o cotidiano dos discentes de modo que, os mesmos, estivessem aptos a correlacionar os termos químicos com os fenômenos que aparecem rotineiramente no seu dia a dia, levando o discente a refletir e raciocinar criticamente. Como afirmam as Orientações Curriculares para o Ensino Médio (OCEM):

O diálogo entre as disciplinas é favorecido quando os professores dos diferentes componentes curriculares focam, como objeto de estudo, o contexto real, as situações de vivência dos alunos, os fenômenos naturais e artificiais, e as aplicações tecnológicas. A complexidade desses objetos exige análises multidimensionais, com a significação de conceitos de diferentes sistemas conceituais, traduzidas nas disciplinas escolares (BRASIL, 2006, p. 102). 
Nessa conjuntura, Almeida et al. (2008, p. 2) relatam que: “[...] se faz necessário a prática de um ensino mais contextualizado, onde se pretende relacionar os conteúdos de Química com o cotidiano dos discentes, respeitando as diversidades de cada um, visando à formação do cidadão, e o exercício de seu senso crítico”.

No decurso da apresentação, foram realizadas algumas indagações ao público presente, com o propósito de estimular a participação e interação do estudante com o mediador, assim, gerando momentos enriquecedores de debates construtivos, com troca de saberes e aquisição de novos conhecimentos, ocasionando uma edificação da aprendizagem entre os discentes envolvidos.

Nesse sentido, os Parâmetros Curriculares Nacionais para o Ensino Médio (PCNs) atestam para importância de estimular a interação entre aluno-aluno e aluno-mediador, pois momentos como estes favorecem o desenvolvimento de competências cognitivas superiores, além de, propiciar formas coletivas de conhecimento (BRASIL, 2000). Cabe ressaltar que nas duas palestras, ocorreu uma interação ativa dos discentes com o palestrante, o que foi primordial para o desenvolvimento da atividade, pois como afirma Freire (1996, p. 23) "quem ensina aprende ao ensinar e quem aprende ensina ao aprender".

Ainda a respeito da palestra 1 (um), foram discutidas algumas curiosidades a respeito das “Cores no céu” (Figura 3), por exemplo: "Por que enxergamos o arco íris?", "Por que o céu é azul?" e "Por que as nuvens são brancas?”. Tais indagações foram realizadas para aguçar a curiosidade dos discentes, no intuito de despertar o senso de investigação, proporcionando uma nova percepção de como enxergar os fenômenos ao nosso redor de uma forma mais atrativa e diversificada.

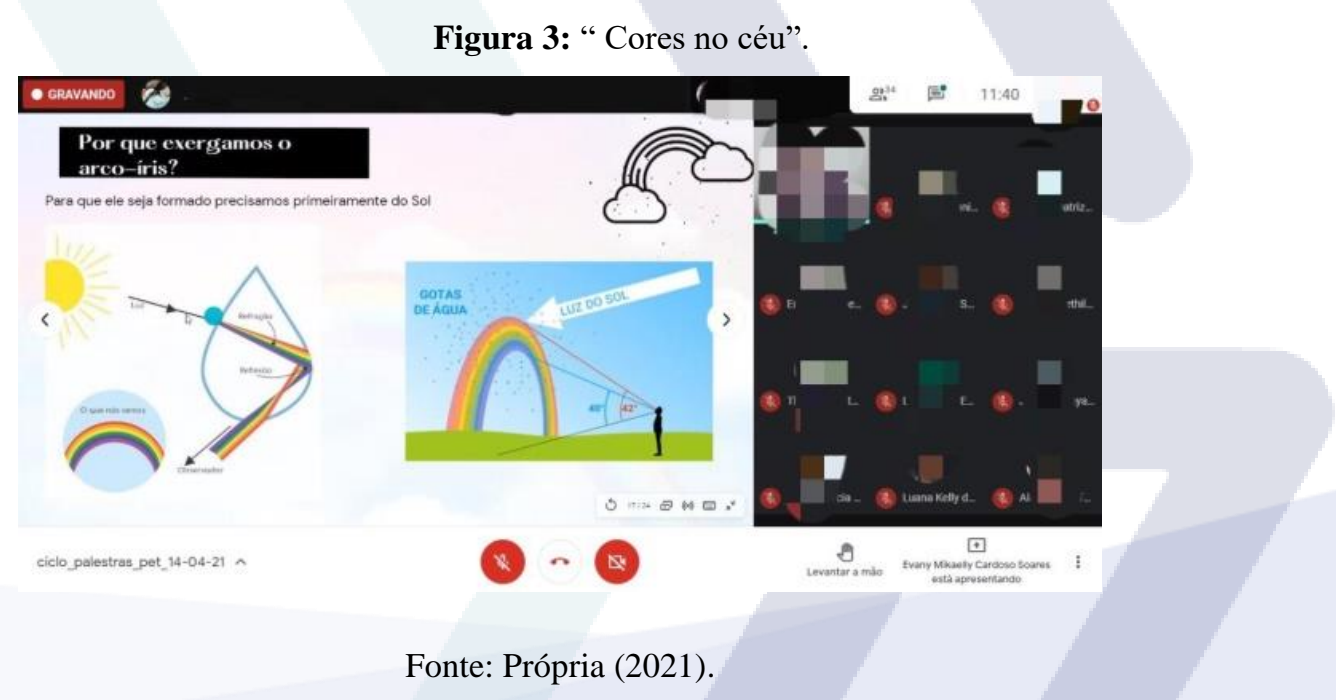

Na palestra 2 (dois), foram abordados tópicos da Química Forense como, testes de caráter investigativos (Figura 4) e presuntivos para identificações de materiais presentes em 
cenas de crimes, como a importância do luminol nas investigações criminalísticas.

Figura 4: "Testes investigativos".

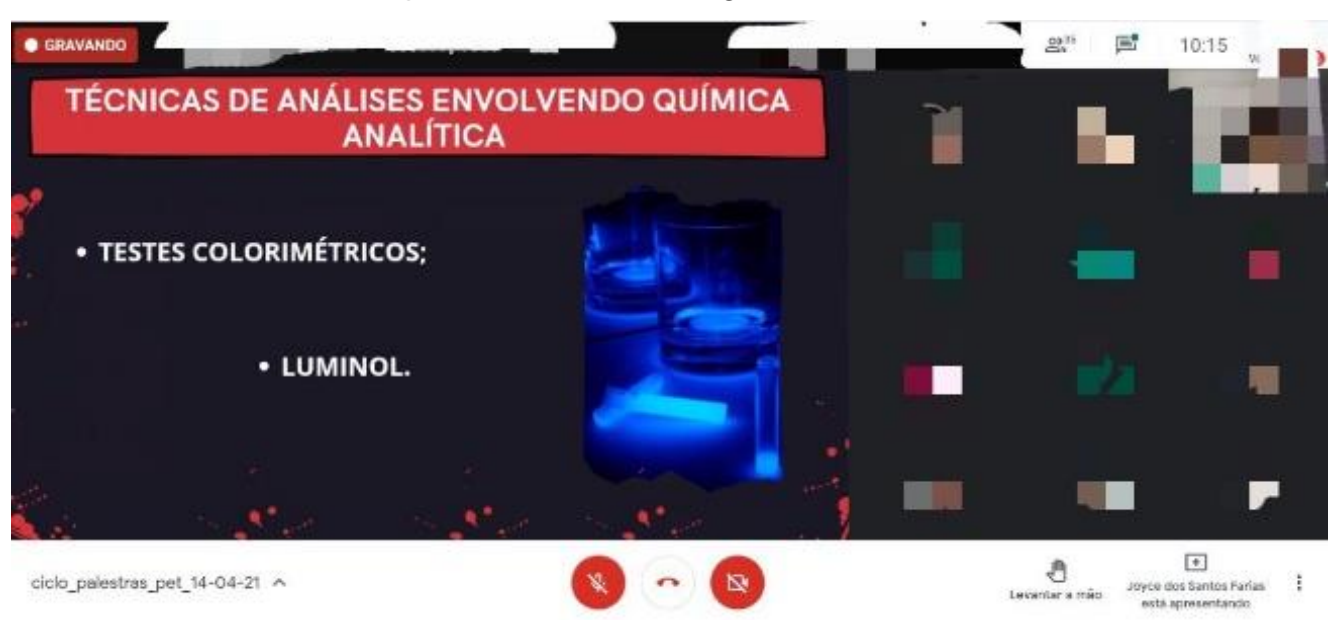

Fonte: Própria (2021).

O luminol é um composto orgânico em pó, no qual sua fórmula molecular é $\mathrm{C}_{8} \mathrm{H}_{7} \mathrm{O}_{2} \mathrm{~N}_{3}$ e esse reagente químico é usado misturando-o ao peróxido de hidrogênio $\left(\mathrm{H}_{2} \mathrm{O}_{2}\right)$ e outros produtos químicos, o que origina uma solução líquida. É oportuno salientar que:

[..] O princípio do luminol é revelar estes traços com uma reação química geradora de luz entre diversas substâncias químicas e a hemoglobina, a proteína portadora do oxigênio no sangue. Nesta reação em particular, os reagentes têm mais energia que os produtos e as moléculas se livram da energia extra sob a forma de fótons de luz visível [...] (LIMA et al, 2011).

Figura 5: "Reação quimiluminescente do luminol, empregando o ferro presente na hemoglobina do sangue como um catalizador."

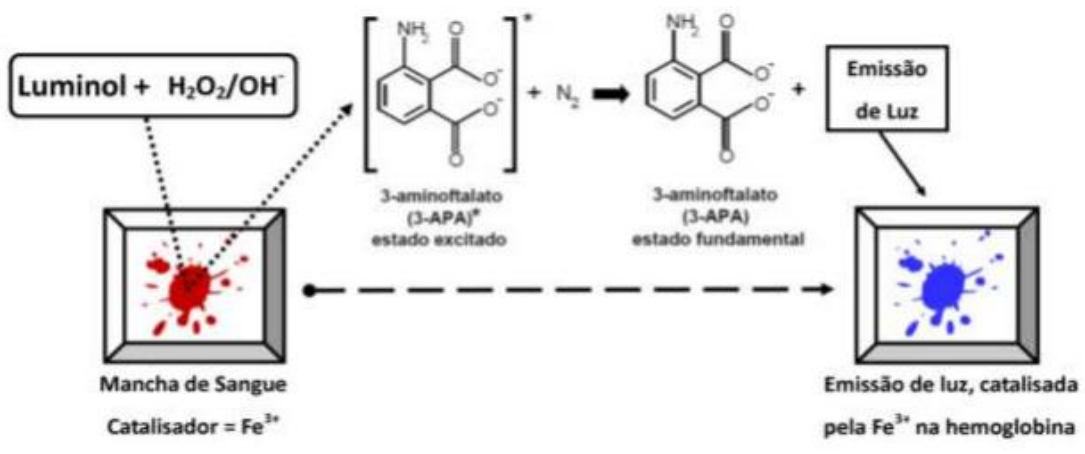

Fonte: CAVALCANTI; BARROS (2016).

Durante a ministração deste conteúdo na palestra 2 , houve uma interação ativa dos discentes pelo chat, com questionamentos e debates, o que tornou a atividade mais enriquecedora. Dessa forma, a Química Forense no ambiente escolar, conseguiu promover a contextualização dos conceitos químicos de forma interdisciplinar, tornando fundamental a 
incrementação de conteúdos científicos tranversais nos cursos de Licenciaturas.

Por fim, no terceiro momento da atividade de ensino, foi aplicado um Questionário Final com 4 (quatro) questões, com o intuito de examinar os dados obtidos e avaliar a satisfação e os conhecimentos que foram adquiridos durante a palestra.

O primeiro questionamento do QF se tratava novamente da Técnica de Associação Livre de Palavras, justamente para comparar os resultados obtidos antes e depois da atividade e analisarmos se as discussões auxiliaram ou não no aprendizado dos ouvintes. Em concernência ao primeiro questionamento do QF, este sublinhava que: Após sua participação na palestra, responda novamente e rapidamente o que lhe vem em mente, quando você pensa sobre os termos "A Química das cores" e "Química Forense". Cite 5 (cinco) palavras em que você pode associar a esses termos. Todos os discentes responderam de forma satisfatória, associando os conceitos químicos com as temáticas supracitadas, como pode-se observar no Quadro 3.

Quadro 3: Resultado do primeiro questionamento do Questionário Final para as duas palestras.

\begin{tabular}{|c|c|c|c|}
\hline \multicolumn{4}{|c|}{$\mathrm{OF}$} \\
\hline \multicolumn{2}{|c|}{ "A Química das cores" } & \multicolumn{2}{|r|}{ _"Química Forense" } \\
\hline Q5 & $\begin{array}{l}\text { Comprimento de onda. } \\
\text { Excitação de elétrons. } \\
\text { Absorção. } \\
\text { Reflexão. } \\
\text { Fótons. }\end{array}$ & Q1 & $\begin{array}{l}\text { Reações químicas. } \\
\text { Luminol. } \\
\text { Reagentes. } \\
\text { Perícia. } \\
\text { Testes colorimétricos. }\end{array}$ \\
\hline Q8 & $\begin{array}{c}\text { Refração. } \\
\text { Frequência da luz. } \\
\text { Feixe refletido. } \\
\text { Compostos químicos. } \\
\text { Espectro visível. }\end{array}$ & $\overline{Q 2}$ & $\begin{array}{c}\text { Luminol. } \\
\text { Reações. } \\
\text { Toxicologia. } \\
\text { Métodos Espectroscópicos. } \\
\text { Balística. }\end{array}$ \\
\hline
\end{tabular}

Fonte: Própria (2021).

Os dados apresentados ressaltam explicitamente a evolução dos discentes no decorrer da atividade, com respostas mais contextualizadas e bem articuladas aos eixos de conhecimento, potencializando assim suas concepções a cerca dos assuntos abordados.

O segundo questionamento do QF pontuava: "O que você achou das palestras supracitadas?". Em concernência a primeira palestra todos os discentes responderam de forma satisfatória, como mostrado nos Q4 e Q7, respectivamente: "Muito boa, bastante informações detalhadas e ricas de conhecimentos"; "Palestra muito boa, tema muito necessário e interessante".

A respeito da segunda palestra, $100 \%$ dos respondentes reagiram indubitavelmente bem à atividade, tal fato pode ser vislumbrado nas respostas dos $\mathbf{Q 9}$ e $\mathbf{Q 3}$, respectivamente: 
"Eu achei que foi uma das melhores palestras que já assisti na vida, achei incrível me encantou do início ao fim, até porque é um assunto que eu gosto bastante, principalmente porque envolve resoluções de crimes, e a Química”; " Muito boa, ela explicou muito bem e além de ter sido uma palestra instrutiva, ainda foi divertida e didática”.

O nível de satisfação dos estudantes atingido nesses resultados respalda o quão significativo foi expor tais temas para futuros profissionais da educação, pois criou maiores possibilidades para a construção do seu conhecimento. Ademais, a utilização dessa metodologia despertou o interesse dos discentes para temáticas que ainda são tratadas modestamente no Ensino de Ciências.

O terceiro questionamento requisitava se o discente já ouviu falar sobre as citadas temáticas antes. Nos dados obtidos, dentre os licenciandos em Química que responderam a esse questionamento, em alusão as duas palestras, alguns deixaram em evidência que sim, outros mencionaram que de forma superficial e poucos respaldaram que não. Alguns relatos dos respondentes em relação a palestra 1 e 2 estão elencados a baixo, no Quadro 4.

Quadro 4: Resultado do terceiro questionamento do Questionário Final para as duas palestras.

\begin{tabular}{|c|c|c|c|}
\hline \multicolumn{2}{|r|}{ "A Química das cores" } & \multicolumn{2}{|r|}{ _"Química Forense" } \\
\hline Q6 & $\begin{array}{l}\text { "Não, mas a palestra foi muito } \\
\text { rica e bem esclarecida." }\end{array}$ & Q13 & $\begin{array}{l}\text { "Não em palestras, mas em séries ou } \\
\text { filmes." }\end{array}$ \\
\hline Q7 & $\begin{array}{l}\text { "Sim, mas não conhecia muitas } \\
\text { das coisas que a palestrante } \\
\text { explicou, muito boa a palestra." }\end{array}$ & Q14 & $\begin{array}{l}\text { "Muito superficialmente em séries de } \\
\text { detetives." }\end{array}$ \\
\hline Q9 & "superficialmente" & Q15 & "Já, mas não dessa forma." \\
\hline
\end{tabular}

Fonte: Própria (2021).

Na quarta e última pergunta do QF, questionava-se: De 0 a 10, o quanto você acha que contribui para o estudante de graduação esse tipo de abordagem tematizada? Em conformidade aos dados coletados, observou-se que os participantes acreditam que as referidas temáticas contribuíram significativamente para a sua formação acadêmica, considerando que todos os respondentes, assinalaram de forma satisfatória, sendo a grande maioria, nota máxima.

Contudo, é oportuno ressalvar que a atividade de ensino promovida pelo PET Química se mostra de grande relevância para o ensino de Química, uma vez que o envolvimento dos estudantes nos dois temas foi enaltecedor. Tal fato proporcionou aos discentes conhecimentos que permitiram a "construção de uma visão de mundo mais articulada e menos fragmentada, 


\section{TEMAS NORTEADORES NO ENSINO DE QUÍMICA}

contribuindo para que o indivíduo se veja como participante de um mundo em constante transformação" (BRASIL, 1999, p. 241).

No que tange aos resultados avaliados, acredita-se que no ensino existam muitas possibilidades para a abordagem das temáticas mencionadas, outrossim, uma delas é a apresentação de palestras com temas pouco difundidos na Licenciatura em Química. Portanto, o "Ciclo de Palestras", como uma nova estratégia pedagógica de ensino, contribuiu ativamente para a formação de educadores mais capacitados, conscientes e críticos.

\section{CONCLUSÕES}

Os currículos educacionais das instituições superiores devem formar cidadãos capacitados para atuarem em diversas áreas do conhecimento. Diante disso, a atividade de ensino "Ciclo de Palestras" trouxe uma abordagem interdisciplinar, com conteúdos relevantes e atuais, que lamentavelmente não são tão presentes nos cursos de Licenciatura em Química do Brasil. Os resultados obtidos demonstraram a importância da atividade, bem como também a evolução dos participantes mediante as ações executadas.

Durante a apresentação das palestras, com debates, discussões e reflexões, foi nítida a construção do conhecimento por parte dos discentes no tocante às temáticas ministradas, "A Química das Cores" e "Química Forense". Portanto, os estudantes além de desenvolverem bastante interesse sobre os temas, mostraram que a presente atividade foi quista e enriquecedora para o processo de aprendizagem, uma vez que abriu novos caminhos para a aquisição de informações importantes na formação de estudantes contemporâneos e estimulou a busca pelo conhecimento científico.

\section{REFERÊNCIAS}

ATKINS, Peter.; JONES, Loretta.; LAVERMAN, Leroy. Princípios de Química, questionando a vida moderna e o meio ambiente. 3. Ed. Porto Alegre: Bookman, 2018.

ALMEIDA, E. C. S. et al. Contextualização do ensino de química: motivando alunos de ensino médio. XVI Encontro Nacional de Ensino de Química (XVI ENEQ) e X Encontro de Educação Química da Bahia (X EDUQUI), Salvador, BA, Brasil-17 a, v. 20, 2008.

BRASIL. Secretaria de Educação Básica. Ministério da Educação. Orientações Curriculares para o Ensino Médio - Linguagens, códigos e suas tecnologias. Brasília, 2006. Disponível 
em: <http://portal.mec.gov.br/seb/arquivos/pdf/book_volume_01_internet.pdf >. Acesso em 04 out. 2012.

BROWN, Theodore L. et al. Química: a ciência central. 9. ed. São Paulo: Pearson Prentice Hall, 2005.

CAVALCANTI .D. R; BARROS .R. M. Escondendo Manchas de Sangue em Locais de Crime: Análise da Ação Antioxidante dos Chás Verde e Preto Sobre o Luminol. Brazilian Journal of Forensic Sciences, Medical Law and Bioethics, v. 6, n. 1, p. 47- 60,2016.

DE LIMA COUTINHO, Maria da Penha; DO BÚ, Emerson. A técnica de associação livre de palavras sobre o prisma do software tri-deux-mots (version 5.2). Revista Campo do Saber, v. 3, n. 1, 2017.

DESLAURIERS J. P. Recherche Qualitative. Montreal: McGraw Hill, 1991.

LIMA, A. S. et al. Química Forense. Revista Eletrônica-UNISEP. Disponível em: $<$ http://unifia. edu. br/revista_eletronica/revistas/gestao_foco/artigos/ano2011/qui_forense. pdf $>$. Acesso em 25/08/2011.

LUDKE, M.; ANDRÉ, M. E. D. A. Pesquisa em educação: abordagens qualitativas. São Paulo: EPU, 1986.

FAZENDA, I. Integração e interdisciplinaridade no ensino brasileiro: efetividade ou ideologia. São Paulo, Loyola, 1979.

FREIRE, Paulo. Pedagogia da autonomia: saberes necessários a prática educativa (Coleção Leitura). São Paulo: Paz e Terra. 1996.

HELFER, Gilson A. et al. Photometrix: An Application for Univariate Calibration and Principal Components Analysis Using Colorimetry on Mobile Devices. Journal of the Brazillian Chemical Society, v. 28, n. 2, p. 328-335, 2017.

KARGER, Barry L. et al. Graduate Education and Research in Forensic Chemistry at Northeast University. 
KRAISIG, Ângela Renata; ROCHA, Thaís Rios; BRAIBANTE, Mara Elisa. Abordagem da temática "cores" em um minicurso para estudantes dos cursos técnico e licenciatura em Química. Revista Debates em Ensino de Química, v. 4, n. 2, fev. 2020.

KRAISIG, Ângela Renata; BRAIBANTE, Mara Elisa Fortes; PAZINATO, Maurícius Selvero. Concepções dos acadêmicos de licenciatura de Ciências da Natureza sobre o tema Cores e processos de Ensino e aprendizagem. Revista Eletrônica de Extensão da URI, Vol. 13, n. 25, p. 67-78, out. 2017. Disponível em: <http://www2.reitoria.uri.br/ vivencias/Numero_025/artigos/pdf/Artigo_07.pdf>. Acesso em: 25 de de 2021.

MOTA, Leandro; DI VITTA, Patrícia Busko. Química forense: utilizando métodos analíticos em favor do poder judiciário. Rev. Acad. Oswaldo Cruz, v. 1, 2014.

ROMÃO, Wanderson et al. Química forense: perspectivas sobre novos métodos analíticos aplicados à documentoscopia, balística e drogas de abuso. Quimica nova, v. 34, n. 10, p. 1717-1728, 2011.

SANTOS, Fábio Rocha; AMARAL, Carmem Lúcia Costa. A química forense como tema contextualizador no ensino de química. Research, Society and Development, v. 9, n. 3, p 1$15,2020$. 